\title{
Application of bilateral internal mammary artery with different configurations in coronary artery bypass grafting
}

\author{
Zengqiang $\mathrm{Han}^{\dagger}$, Guodong Zhang ${ }^{\dagger}$, Shenglong Chen, Gang Liu and Yu Chen º
}

\begin{abstract}
Background: A large number of studies have shown that BIMA grafting is superior to single internal mammary artery grafting in cardiac function protection and long-term survival after surgery. While, there is still no consensus on how is the best configuration to use BIMA. This study aims to compare intraoperative blood flow, early clinical results and early postoperative patency of different configurations of BIMA.

Methods: There were 74 patients who underwent CABGs with bilateral internal mammary artery with different configurations we included. According to the different target territories that RIMA grafted to, the patients were divided into bilateral group (group I) with 20 cases and left group (group II) with 54 cases. Intraoperative blood flow, early clinical results and early postoperative patency of different configurations of BIMA were compared.

Results: There was no difference in the early postoperative death and major complications between group I and Group II(P>0.05). Compared with the LIMA in group II, the LIMA in group I had a slightly higher DF value (76.7 \pm 6.2 vs $73.1 \pm 6.8, P=0.040)$. Compared with the RIMA in group II, the RIMA in group I had a slightly higher MGF $(51.7 \pm$ $34.4 \mathrm{ml} / \mathrm{min}$ vs $31.4 \pm 21.4 \mathrm{ml} / \mathrm{min}, P=0.024)$. There was no difference in the other TTFM parameters of LIMA and RIMA between group I and Group II(P>0.05). Further subgroup analysis revealed that compared with free RIMA in group II, in situ RIMA had a higher DF value $(71.4 \pm 7.8$ vs $61.8 \pm 18.1, P=0.025)$. The PI of LIMA in free RIMA subgroup was higher than the PI of LIMA in in-situ RIMA subgroup ( $3.0 \pm 1.6$ vs $2.1 \pm 1.0, P=0.018$ ). The results of early postoperative CTA examination showed that all IMAs grafts were completely patent.

Conclusions: The use of BIMA for CABG is safe and efficacious, RIMA used in right coronary artery received more satisfactory graft flow. BIMA with no stenosis and occlusion in the early stage, therefore is the ideal and stable coronary bypass graft.
\end{abstract}

Keywords: Coronary artery bypass graft, Internal mammary arteries, Transit time flow measurement

\section{Background}

Since Robert Goetz first performed and published the coronary artery bypass graft surgery in humans in 1961, now CABG has become an important revascularization methods of coronary heart disease [1]. Since the mid-

\footnotetext{
* Correspondence: chenyudoctor@163.com

* Correspondence: chenyudoctor@163.com
'Zengqiang Han and Guodong Zhang contributed equally to this work. Cardiac Surgery Department, Peking University People's Hospital, Beiling 100044, China
}

1980s, owing to the high patency, the use of the left internal mammary artery (LIMA) for left anterior descending artery (LAD) grafting has been a cornerstone of CABG surgery [2]. Previous studies showed that the right internal mammal artery (RIMA) has the same anatomical structure and physiological function as the LIMA, and has the same long-term patency rate as LIMA. A large number of studies have shown that BIMA grafting is superior to single internal mammary

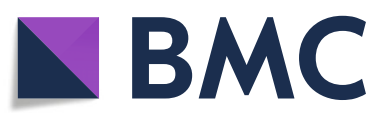

(c) The Author(s). 2020 Open Access This article is licensed under a Creative Commons Attribution 4.0 International License, which permits use, sharing, adaptation, distribution and reproduction in any medium or format, as long as you give appropriate credit to the original author(s) and the source, provide a link to the Creative Commons licence, and indicate if changes were made. The images or other third party material in this article are included in the article's Creative Commons licence, unless indicated otherwise in a credit line to the material. If material is not included in the article's Creative Commons licence and your intended use is not permitted by statutory regulation or exceeds the permitted use, you will need to obtain permission directly from the copyright holder. To view a copy of this licence, visit http://creativecommons.org/licenses/by/4.0/. The Creative Commons Public Domain Dedication waiver (http://creativecommons.org/publicdomain/zero/1.0/) applies to the data made available in this article, unless otherwise stated in a credit line to the data. 
artery grafting in cardiac function protection and longterm survival after surgery [3-5]. While, owing to high technical requirements, the long operation time, and high incidence rate of sternal wound complications, the use of BIMA grafting is limited, about $5 \%$ worldwide, and it is only recommended for younger patients [6]. And there is still no consensus on how is the best configuration to use BIMA [5]. This study aims to compare intraoperative blood flow, early clinical results and early postoperative patency of different configurations of BIMA.

\section{Material and methods Study population}

Data for isolated CABG were retrospectively collected from January 1, 2018 to July 31, 2020, from the Peking University People's Hospital database. Exclusion criteria: (1) coronary artery disease is unsuitable or unnecessary for BIMA;(2) Combined with subclavian artery stenosis; (3) Preoperative IMA ultrasound indicated that the IMA was fine, narrow or calcified;(4) With concomitant additional procedures. There were 74 patients who underwent CABGs with bilateral internal mammary artery with different configurations we included. According to the different target territories that RIMA grafted to, the patients were divided into bilateral group (group I) with 20 cases and left group (group II) with 54 cases. This study was approved by our institutional Review Board /Ethics Committee. Consent for individual use of data was waived because of the nature of the study and previous approval for the use of such data at the time of operative consent.

\section{Surgical methods}

All patients underwent CABGs through a median full sternotomy. Stabilization of the target coronary arteries was accomplished with a tissue stabilizer (Octopus, Medtronic Corporation, Minneapolis, MN) and an intracoronary shunt (Medtronic Corporation, Minneapolis, $\mathrm{MN}$ ) was used during off-pump CABGs. In on-pump CABGs, cardiopulmonary bypass was established after standard ascending aorta cannulation and 2-stage venous cannulation of the right atrium, all anastomosis were performed after cardiac arrest. Fifty-six cases of LIMA were harvested by pedicled method, and 18 cases were harvested by the skeletonized method. RIMAs were all harvested by the skeletonized method to maximize the length of the internal mammary artery. After systemic heparinization, the distal end of IMAs were cut, which were protected by poppy alkali gauze.

BIMA configurations were as follows:

Group I (20 cases): In situ RIMA to right coronary artery or posterior descending artery with in situ LIMA to left anterior descending artery (Fig. 1).

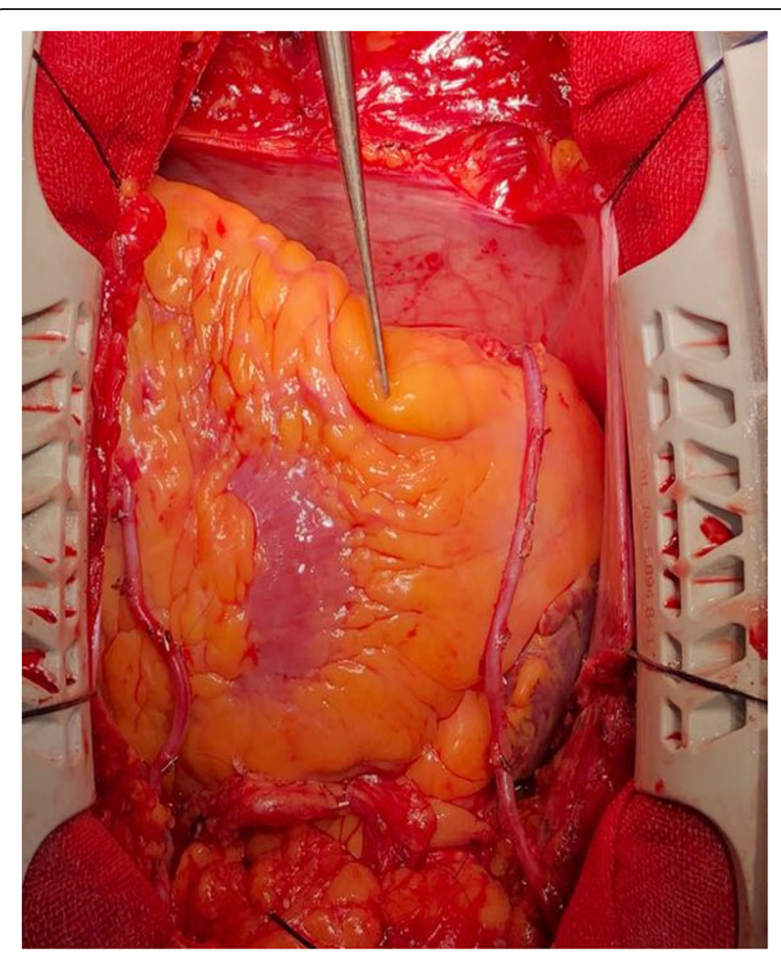

Fig. 1 In situ RIMA to right coronary artery or posterior descending artery with in situ LIMA to left anterior descending artery. LIMA, left internal mammary artery; RIMA, right internal mammary artery

Group II (54 cases) was divided into: (1) In situ RIMA to LAD with in situ LIMA to diagonal branch (D) or left circumflex branch (LCX)(17 cases) (Fig. 2a).(2) In situ RIMA to D or LCX with in situ LIMA to LAD (14 cases) (Fig. 2b).(3) In situ LIMA to LAD and LIMA-Y-free RIMA to D or LCX (13 cases).(4) In situ LIMA to LAD with aorta-free RIMA to D or LCX (10 cases). Other target territories were revascularized by the great saphenous vein or radial artery.

\section{Preoperative internal mammary artery ultrasonography examination}

Preoperative blood flow parameters of IMAs were measured by transthoracic doppler ultrasonography machine (APLIO500 TUS-A500, Probe: PLT-704SBT and PVT712BT). All preoperative internal mammal artery ultrasonography was performed by the same senior ultrasonologist.

\section{Intraoperative transit time flow measurement}

The transit time flow of the grafts was measured by The VeriQ system TTFM device (MediStim Inc., Oslo, Norway), equipped with2,3 or 4-mm probes, depending on the size of the graft, under stable haemodynamic conditions without the support of a mechanical device such as cardiopulmonary bypass or an intra-aortic balloon pump. The parameter yielded by TTFM system including(i) the mean graft flow volume (MGF, $\mathrm{ml} / \mathrm{min}$ ), (ii) 


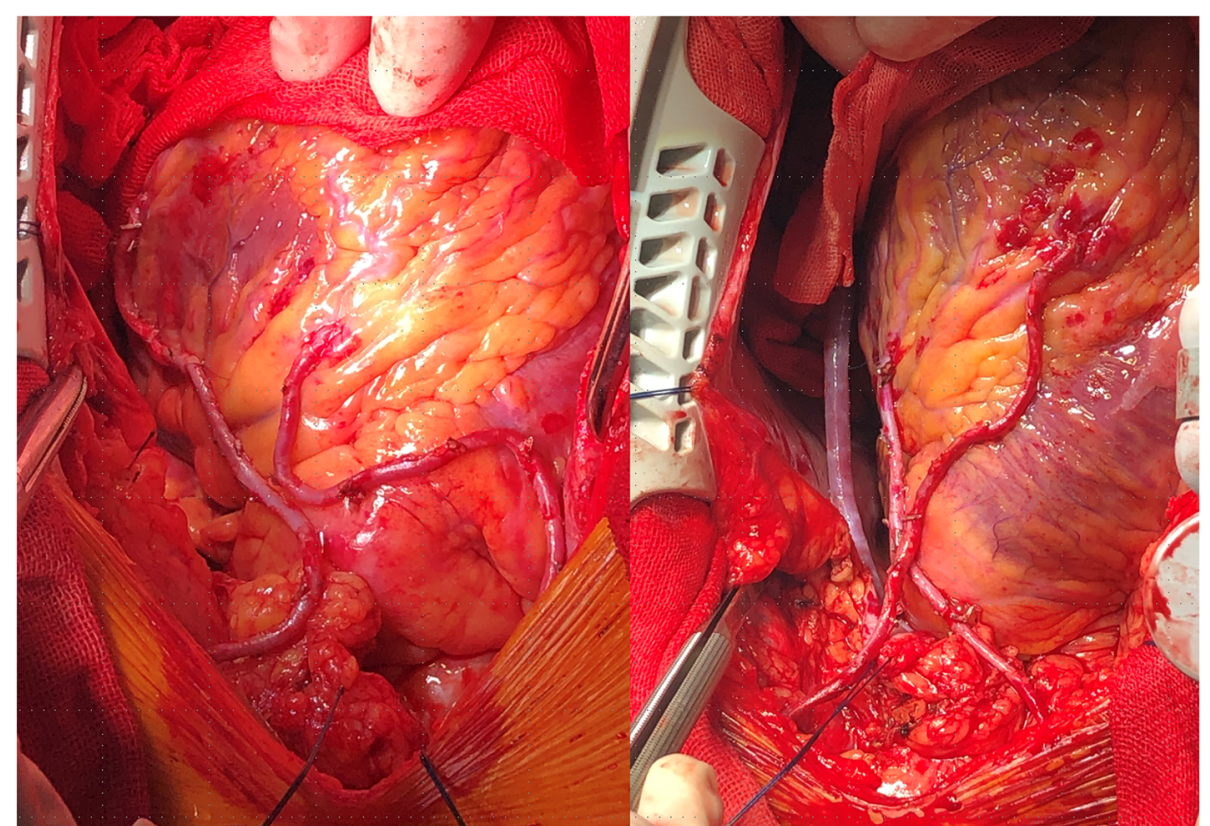

Fig. 2 a In situ RIMA to LAD with in situ LIMA to diagonal branch. b In situ RIMA to LCX with in situ LIMA to LAD. LAD, left anterior descending artery; LIMA, left internal mammary artery; RIMA, right internal mammary artery; TTFM, transit-time flow measurement

the pulse index calculated as (PI, maximum flow volume-minimum flow volume)/(mean flow volume) and (iii) the DF, calculated as (flow volume of the diastolic phase)/(flow volume of the systolic phase + flow volume of the diastolic phase). Satisfactory blood flow parameters criteria: $1, \mathrm{ACI}>50 \%$; 2 , The shape of blood flow waveform is stable and repeatable; $3, \mathrm{PI}<5, \mathrm{MGF}>15 \mathrm{ml} / \mathrm{min}$. If sufficient graft flow was not obtained, graft revision was considered and performed until diastolic graft flow was confirmed.

\section{Postoperative management}

Postoperatively, aspirin, nitroglycerine and $\beta$ - blocker were prescribed on postoperative day 1 . The patients were routinely examined by cardiac CT scanning prior to discharge from the hospital unless they had grade 3 or more chronic kidney disease.

\section{Statistical analysis}

The database was established by EpiDate3.1 software, the data were input twice in parallel. The final analysis database is formed after logical error checking and sorting of the input data and analysis and processing of outliers. Continuous variables were expressed as means \pm SDs; if the data conformed to a normal distribution, the two groups were compared using an independent samples $\mathrm{t}$ test, and multiple groups were compared using variance analysis. For nonnormally distributed data, Wilcoxon rank-sum tests were used for comparisons between two groups, and Kruskal-Wallis $\mathrm{H}$ tests were used for comparison between multiple groups. Categorical variables were described as percentages (rates); comparisons between two groups were performed using Pearson's $X^{2}$ test or Fischer's exact test as appropriate. $P<$ 0.05 was considered statistically significant. All analyses were performed in SPSS version 23.

\section{Results}

Baseline patient characteristics shown in Table 1. There was no difference in the baseline patient characteristics between group I and Group II $(P>0.05)$.

\section{The comparison of early postoperative death and major} complications between group I and group II

One case died of low cardiac output syndrome due to perioperative myocardial infarction early postoperatively in group II (1.35\%). There was no difference in total operation time $(5.2 \pm 1.2$ vs $5.5 \pm 1.2 \mathrm{~h}, P=0.457)$ between group I and Group II, however the heparin-protamine time of group II was longer than that of group I $(138.9 \pm 41.0$ vs173.4 $\pm 58.9 \mathrm{~min}, P=0.019)$. There was no difference in the early postoperative death and major complications between group I and Group $\mathrm{II}(\mathrm{P}>0.05)$ (Table 2).

The comparison of intraoperative blood flow parameters between group I and group II

Compared with the LIMA in group II, the LIMA in group I had a slightly higher DF value $(76.7 \pm 6.2$ vs $73.1 \pm 6.8, P=0.040)$. Compared with the RIMA in group 
Table 1 Demographic and clinical characteristics

\begin{tabular}{llll}
\hline Items & Group I( $\boldsymbol{n = 2 0 )}$ & Group II( $\boldsymbol{n}=\mathbf{5 4})$ & $\mathbf{P}$ \\
\hline Gender & & & 1.000 \\
$\quad$ Male & $18(90.0 \%)$ & $49(90.7 \%)$ & \\
$\quad$ Female & $2(10.0 \%)$ & $5(9.3 \%)$ & \\
Age & $58.2 \pm 8.9$ & $56.4 \pm 10.4$ & 0.492 \\
BMI (kg/m2) & $25.6 \pm 2.8$ & $25.6 \pm 3.1$ & 0.952 \\
Diabetes (n, \%) & $9(45.0 \%)$ & $16(29.6 \%)$ & 0.214 \\
Hypertension (n, \%) & $11(55.0 \%)$ & $30(55.6 \%)$ & 0.966 \\
Hyperlipidemia (n, \%) & $8(40.0 \%)$ & $18(33.3 \%)$ & 0.594 \\
PVD (n, \%) & $1(5.0 \%)$ & $7(13.0 \%)$ & 0.435 \\
previous PCl & $5(25.0 \%)$ & $4(7.4 \%)$ & 0.054 \\
COPD & $1(5.0 \%)$ & $1(1.9 \%)$ & 0.470 \\
LM disease & $2(10.0 \%)$ & $8(14.8 \%)$ & 0.719 \\
LVEF(\%) & $61.9 \pm 10.7$ & $62.0 \pm 10.6$ & 0.971 \\
Cr (mol/L) & $72.8 \pm 12.9$ & $76.6 \pm 16.0$ & 0.236 \\
\hline BMI body mas & &
\end{tabular}

$B M I$ body mass index, COPD chronic obstructive pulmonary disease, $P V D$ peripheral vascular diseases, LVEF left ventricular ejection fraction, $L M$ left main disease

II, the RIMA in group I had a slightly higher MGF $(51.7 \pm 34.4 \mathrm{ml} / \mathrm{min}$ vs $31.4 \pm 21.4 \mathrm{ml} / \mathrm{min}, \quad P=0.024)$. There was no difference in the other TTFM parameters of LIMA and RIMA between group I and Group $\mathrm{II}(\mathrm{P}>0.05)$ (Table 3$)$. Further subgroup analysis revealed that compared with free RIMA in group II, in situ RIMA had a higher DF value $(71.4 \pm 7.8$ vs $61.8 \pm 18.1, P=$ 0.025). The PI of LIMA in free RIMA subgroup was higher than the PI of LIMA in in-situ RIMA subgroup $(3.0 \pm 1.6$ vs $2.1 \pm 1.0, P=0.018)$ (Table 4$)$.

Table 2 Baseline procedural characteristics of group I and group II

\begin{tabular}{llll}
\hline Items & Group I $(\boldsymbol{n}=\mathbf{2 0})$ & Group II $(\boldsymbol{n}=\mathbf{5 4})$ & $\mathbf{P}$ \\
\hline Operation time(h) & $5.2 \pm 1.2$ & $5.5 \pm 1.2$ & 0.457 \\
$\begin{array}{l}\text { Heparin protamine } \\
\text { time (min) }\end{array}$ & $138.9 \pm 41.0$ & $173.4 \pm 58.9$ & 0.019 \\
Off-pump & $13(65.0 \%)$ & $36(66.7 \%)$ & 0.893 \\
Number of anastomosis & $3.2 \pm 0.9$ & $3.3 \pm 0.8$ & 0.621 \\
Perioperative MI & $1(5.0)$ & $2(3.7 \%)$ & 1.000 \\
CRRT (n, \%) & $1(5.0 \%)$ & $7(13.0 \%)$ & 0.435 \\
Volume of blood (ml) & $760.0 \pm 373.3$ & $772.2 \pm 516.1$ & 0.923 \\
RBC transfusion(U) & $2.1 \pm 2.4$ & $2.4 \pm 4.2$ & 0.738 \\
Re- thoracotomy & $0(0)$ & $2(3.7 \%)$ & 1.000 \\
Sternal complication & $1(5.0 \%)$ & $1(1.9 \%)$ & 0.470 \\
Ventilator time(h) & $17.1 \pm 17.2$ & $22.8 \pm 42.4$ & 0.567 \\
ICU stay time(h) & $43.9 \pm 39.5$ & $46.7 \pm 54.6$ & 0.835 \\
Post-operative stay time(d) & $10.7 \pm 5.0$ & $11.1 \pm 7.5$ & 0.827 \\
\hline CRRT continuous renal repla & & & \\
Carem & & &
\end{tabular}

CRRT continuous renal replacement therapy, $R B C$ red blood cell, ICU intensive care unit
Table 3 The comparison of TTFM parameters between Group I and Group II

\begin{tabular}{llll}
\hline TTFM & Group I $(\boldsymbol{n}=\mathbf{2 0})$ & Group II $(\boldsymbol{n}=\mathbf{5 4})$ & $\mathbf{P}$ \\
\hline LIMA-MF & $30.7 \pm 10.3$ & $32.3 .8 \pm 22.3$ & 0.671 \\
LIMA-PI & $2.2 \pm 0.6$ & $2.5 \pm 1.4$ & 0.288 \\
LIMA-DF & $76.7 \pm 6.2$ & $73.1 \pm 6.8$ & 0.040 \\
RIMA-MF & $51.7 \pm 34.4$ & $31.4 \pm 21.4$ & 0.024 \\
RIMA-PI & $2.1 \pm 1.1$ & $2.7 \pm 2.5$ & 0.307 \\
RIMA-DF & $64.8 \pm 6.8$ & $67.2 \pm 14.0$ & 0.332 \\
BIMA-MF & $78.0 \pm 42.7$ & $62.2 .1 \pm 37.8$ & 0.128
\end{tabular}

TTFM transit time flow measurement, LIMA left internal mammary artery, RIMA left internal mammary artery, MGF mean graft flow, $P /$ pulse index, $D F$ diastolic flow fraction

Results of the CT angiography examined before discharge A total of 74 patients were examined for coronary CT angiography before discharge. The results of early postoperative CTA examination showed that all IMAs grafts were completely patent.

\section{Discussion}

Arterial conduits, including the left internal mammal artery [7], bilateral internal mammal arteries [8], and the radial artery have excellent patency [9], resulting in better long-term survival in comparison with CABG using the saphenous vein graft. The strategy of in situ LIMA grafting to the LAD (LIMA-LAD) is considered the "gold standard" of coronary revascularization [10]. Previous studies proved a substantial survival benefit from both right internal mammary artery and radial artery used as the second conduit compared with single internal mammary artery plus saphenous vein graft [11, 12]. Owing to not need extra incisions and the advantages of not being spasmodic, RIMA has been the first choice as the second arterial conduit. However, due to high technical requirements, the long operation time, and high incidence rate of sternal wound complications, the use of BIMA grafting is limited, about 5\% worldwide,

Table 4 The comparison of TTFM parameters between in situ RIMA and free RIMA

\begin{tabular}{llll}
\hline TTFM & In situ RIMA $(\boldsymbol{n}=\mathbf{3 1})$ & Free RIMA $(\boldsymbol{n}=\mathbf{2 3})$ & $\mathbf{P}$ \\
\hline LIMA-MF & $35.9 \pm 24.7$ & $27.4 \pm 18.0$ & 0.168 \\
LIMA-PI & $2.1 \pm 1.0$ & $3.0 \pm 1.6$ & 0.018 \\
LIMA-DF & $72.1 \pm 6.2$ & $74.5 \pm 7.5$ & 0.203 \\
RIMA-MF & $33.4 \pm 24.1$ & $28.9 \pm 17.2$ & 0.453 \\
RIMA-PI & $2.3 \pm 0.6$ & $3.2 \pm 3.7$ & 0.223 \\
RIMA-DF & $71.4 \pm 7.8$ & $61.8 \pm 18.1$ & 0.025 \\
RIMA-MF & $66.7 \pm 45.1$ & $56.3 \pm 24.4$ & 0.282 \\
\hline
\end{tabular}

TTFM transit time flow measurement, LIMA left internal mammary artery, RIMA left internal mammary artery, MGF mean graft flow, PI pulse index, DF diastolic flow fraction 
and it is only recommended for younger patients [6]. From 1999 to 2009, the application proportion of BIMA in the United States was stable at around 4\%, with almost no significant change [13]. The application proportion of BIMA in Europe was also less than 10\% [14]. We used BIMA to perform CABG in 74 patients and achieved satisfactory short-term efficacy, but the longterm effect still needs further follow-up observation. BIMA harvested by the skeletonized method can better retain collateral vessels that supply the sternum, which might help reduce the probability of nonunion and deep infection of the sternum [15]. In our study, 56 cases of LIMA were harvested by pedicled method, and 18 cases were harvested by the skeletonized method. RIMAs were all harvested by the skeletonized method. Minor sternal incision complications occurred in 2 patients, including 1 diabetic patient with BMI of 27.7 and the other case without diabetes but had a BMI of 34.3. There was no deep sternal infection in 74 cases. We suggest that RIMA should be harvested by skeletonized method because of its long walking path. At the same time, LIMA can be routinely obtained with pedicle method in most patients, which reduce the operation time and does not increase the risk of sternal complications. BIMA should be routinely harvested by the skeletonized method in patients with obesity, diabetes, or severe respiratory disease. During the operation, attention should be paid to avoid sternal fracture caused by excessive retraction of sternal retractor and to strengthen the protection of sternal incision. Sternal ligation belt should be used as far as possible to reduce postoperative sternal cutting, and " 8 " suture should be used when using steel wire. More attention should be paid to the strict monitoring and control of blood glucose after operation.

At present, there is still no consensus about the optimal configuration of BIMA, different groups configurations may affect the short-and long-term outcomes of patients. The lack of evidence for the strategy of configuration makes the choice of BIMA more uncertain, which limits its promotion. Sheila et al. reported that the long-term outcome of BIMA used for revascularization in the left coronary territories was better than that in left and right coronary territories respectively. The possible explanation may be that the left coronary is more important than the right coronary system [16]. The graft failure occurred in left coronary system has more significant negative effect than that occurred in right coronary system. However, this study showed that the blood flow was better when BIMA was used in the left and right coronary arteries respectively than when BIMA was used in the left coronary arteries only, which may related to that about $80 \%$ Chinese people are right-coronal dominant type. Previous studies have showed that in situ RIMA used for the left coronary system increases the difficulty second operation. This study confirmed that RIMA can also achieve satisfactory blood flow in the right coronal system. A meta-analysis reported by Yanagawa et al., which included 8 studies, showed that the shortterm and long-term outcomes of in situ BIMA and composite "Y" conduit were similar, but the results were significantly different between different studies [17]. In this study, in situ LIMA was used in all cases, and group II was divided into two subgroups, in situ and free RIMA, comparison between subgroups showed that in situ RIMA could achieve better blood flow, which was consistent with previous literature reports [18]. When BIMA was completely used in the left coronary system, there were no statistically significant differences between LIMA-LAD and RIMA-LAD in terms of MF, PI or DF. When the length of RIMA was not enough, free RIMA was used to form a "Y -shaped" configuration with in situ LIMA [13] or directly anastomosed to the ascending aorta [2] to revascularize the D or LCX. There was no significant difference between the two groups in terms of PI, MGF and DF. When the proximal diameter of the RIMA is thick enough, it can be directly anastomosed to the ascending aorta to avoid the uncertain impact on the LIMA-LAD. A total of 74 patients were examined for coronary CT angiography before discharge and showed that all IMAs grafts were completely patent.

\section{Limitations}

Several limitations of our study should be recognized. The first and most important limitation of this study was its descriptive nature, using a relatively small cohort of patients at a single institution. Second, the lack of long-term follow-up data was a limitation.

\section{Conclusions}

The use of BIMA for CABG is safe and efficacious, RIMA used in right coronary artery received more satisfactory graft flow. BIMA with different configurations and harvest method can be choose according the different target conditions.

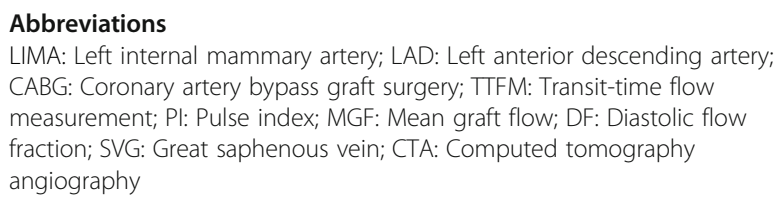

Acknowledgements

Not applicable.

Authors' contributions

Yu Chen is the corresponding author. Guodong Zhang and Zengqiang Han conceived of the study and participated in its design and coordination. Yu Chen, Gang Liu and Shenglong Chen helped to draft the manuscript. All authors read and approved the final manuscript. 


\section{Funding}

To establish and optimize the combination of AAS clinical treatment strategies and techniques (2145000054).

\section{Availability of data and materials}

Data will be made available on request.

Ethics approval and consent to participate

Not applicable.

\section{Consent for publication}

We received explicit consent from the patient.

\section{Competing interests}

The authors declare that they have no competing interests.

Received: 1 September 2020 Accepted: 4 December 2020

Published online: 06 January 2021

\section{References}

1. EAV R. Fifty Years of Coronary Artery Bypass Graft Surgery. Brazilian J Cardiovasc Surg. 2017;32(4):II-III.

2. Gaudino M, Antoniades C, Benedetto U, Deb S, Di Franco A, Di Giammarco G, Fremes S, Glineur D, Grau J, He G-W, et al. Mechanisms, consequences, and prevention of coronary graft failure. Circulation. 2017;136(18):1749-64.

3. Lytle BW. Bilateral internal thoracic artery grafting. Ann Cardiothoracic Surg. 2013;2(4):485-92

4. Kurlansky PA, Traad EA, Dorman MJ, Galbut DL, Zucker M, Ebra G. Thirty-year follow-up defines survival benefit for second internal mammary artery in propensity-matched groups. Ann Thorac Surg. 2010;90(1):101-8.

5. Are all forms of total arterial revascularization equal? A comparison of single versus bilateral internal thoracic artery grafting strategies.[J]. J Thorac Cardiovasc Surgery. 2015;150(6):1526-1534.e3.

6. Guo Y, Wang X, He S, Shu Y, Wang T, Chen Z. Short-term results of bilateral internal mammary arterial grafting for patients aged 60-75 years - a retrospective study. J Cardiothorac Surg. 2019;14(1):175.

7. Loop, Floyd D, Lytle, Bruce W, Cosgrove, Delos M. Influence of the internalmammary-artery graft on 10-year survival and other cardiac events. []]. N Engl J Med. 1986;314(1):1-6.

8. Lytle BW, Blackstone EH, Sabik JF, Houghtaling P, Loop FD, Cosgrove DM. The effect of bilateral internal thoracic artery grafting on survival during 20 postoperative years. Ann Thorac Surg. 2004;78(6):2005-14

9. Anoar, Zacharias, Robert, Habib, Thomas, Schwann, Christopher: Improved survival with radial artery versus vein conduits in coronary bypass surgery with left internal thoracic artery to left anterior descending artery grafting. Circulation 2004;109:1489-96.

10. Benedetto $U$, Amrani M, Gaer J, et al. The influence of bilateral internal mammary arteries on short- and long-term outcomes: a propensity score matching in accordance with current recommendations.[J]. J Thoracic Cardiovasc Surgery. 2014;148(6):2699-705.

11. Galbut DL, Kurlansky PA, Traad EA, Dorman MJ, Zucker M, Ebra G. Bilateral internal thoracic artery grafting improves long-term survival in patients with reduced ejection fraction: A propensity-matched study with 30-year followup. J Thoracic Cardiovasc Surg. 2012;143(4):844-53 e844.

12. Schwann TA, Al-Shaar L, Tranbaugh RF, Dimitrova KR, Hoffman DM, Geller CM, Engoren MC, Bonnell MR, Habib RH. Multi Versus Single Arterial Coronary Bypass Graft Surgery Across the Ejection Fraction Spectrum[J]. Ann Thoracic Surg. 2015;100(3):810-18

13. Falk V. Coronary bypass grafting with bilateral internal thoracic arteries, Heart. 2013;99(12):821.

14. Persson M, Sartipy U. Bilateral versus single internal thoracic artery grafts. Curr Cardiol Rep. 2018;20(1):4

15. Boodhwani M. Skeletonized internal thoracic artery harvest reduces pain and dysesthesia and improves sternal perfusion after coronary artery bypass surgery: a randomized, double-blind, within-patient comparison. Circulation. 2006;114(8):766-73.

16. Schmidt SE, Jones JW, PhD, Thornby JI, lii CCM, PhD, Jr ACB, MD: Improved Survival With Multiple Left-Sided Bilateral Internal Thoracic Artery Grafts. Annals Thoracic Surgery. 1997;64(1):0-15.
17. Yanagawa B, Verma $S$, Jüni $P$, Tam DY, Friedrich JO. A systematic review and meta-analysis of in situ versus composite bilateral internal thoracic artery grafting. J Thoracic Cardiovasc Surg. 2016;153(5):1108.

18. Verhelst R, Etienne PY, El Khoury G, Noirhomme P, Rubay J, Dion R. Free internal mammary artery graft in myocardial revascularization. Cardiovascular Surgery. 1996:4(2):212-16.

\section{Publisher's Note}

Springer Nature remains neutral with regard to jurisdictional claims in published maps and institutional affiliations.
Ready to submit your research? Choose BMC and benefit from:

- fast, convenient online submission

- thorough peer review by experienced researchers in your field

- rapid publication on acceptance

- support for research data, including large and complex data types

- gold Open Access which fosters wider collaboration and increased citations

- maximum visibility for your research: over $100 \mathrm{M}$ website views per year

At BMC, research is always in progress.

Learn more biomedcentral.com/submissions 